\title{
BMJ Open Factors associated with adherence to COVID-19 prevention measures in the Democratic Republic of the Congo (DRC): results of an online survey
}

\author{
John Dinanga Ditekemena (D) ,' Dalau Mukadi Nkamba, ${ }^{1,2}$ \\ Hypolite Mavoko Muhindo, ${ }^{3}$ Joseph Nelson Fodjo Siewe (D) , ${ }^{4}$ Christophe Luhata, ${ }^{1}$ \\ Rafael Van den Bergh, ${ }^{4}$ Antoinette Tshefu Kitoto, ${ }^{1}$ Wim Van Damme, \\ Jean Jacques Muyembe, ${ }^{6}$ Robert Colebunders ${ }^{4}$
}

To cite: Ditekemena JD, Nkamba DM, Muhindo HM, et al. Factors associated with adherence to COVID-19 prevention measures in the Democratic Republic of the Congo (DRC): results of an online survey. BMJ Open 2021;11:e043356. doi:10.1136/ bmjopen-2020-043356

- Prepublication history and additional material for this paper are available online. To view these files, please visit the journal online (http://dx.doi. org/10.1136/bmjopen-2020043356).

Received 31 July 2020 Revised 23 November 2020 Accepted 26 November 2020

Check for updates

(C) Author(s) (or their employer(s)) 2021. Re-use permitted under CC BY-NC. No commercial re-use. See rights and permissions. Published by BMJ.

For numbered affiliations see end of article.

Correspondence to

Dr John Dinanga Ditekemena; jditekemena@hotmail.fr

\section{ABSTRACT}

Objectives We aimed to assess the level of adherence to COVID-19 preventive measures in the Democratic Republic of the Congo (DRC) and to identify factors associated with non-adherence.

Design A cross-sectional population-based online survey. Settings The study was conducted in 22 provinces of the DRC. Five provinces with a satisfactory number of respondents were included in the analysis: Haut Katanga, Kasaï-Central, Kasaï-Oriental, Kinshasa and North Kivu.

Participants The participants were people aged $\geq 18$ years, living in the DRC. A total of 3268 participants were included in the study analysis.

Interventions Both convenience sampling (surveyors themselves contacted potential participants in different districts) and snowball sampling (the participants were requested to share the link of the questionnaire with their contacts) methods were used.

Primary and secondary outcome measures We computed adherence scores using responses to 10 questions concerning COVID-19 preventive measures recommended by the WHO and the DRC Ministry of Health. We used logistic regression analysis with generalised estimating equations to identify factors of poor adherence. We also asked about the presence or absence of flulike symptoms during the preceding 14 days, whether a COVID-19 test was done and the test result.

Results Data from 3268 participants were analysed. Face masks were not used by 1789 (54.7\%) participants. Non-adherence to physical distancing was reported by 1364 (41.7\%) participants. 501 (15.3\%) participants did not observe regular handwashing. Five variables were associated with poor adherence: lower education level, living with other people at home, being jobless/students, living with a partner and not being a healthcare worker.

Conclusion Despite compulsory restrictions imposed by the government, only about half of the respondents adhered to COVID-19 preventive measures in the DRC. Disparities across the provinces are remarkable. There is an urgent need to further explore the reasons for these disparities and factors associated with non-adherence.
Strengths and limitations of this study

- This is the first online survey about COVID-19 preventive behaviour and COVID-19-like symptoms in the Democratic Republic of the Congo (DRC).

- Data were obtained from five provinces of the DRC.

- Respondents were mainly recruited from among more educated individuals who often had more access to internet and smartphones.

- Self-reports may be influenced by recall bias and social desirability.

\section{INTRODUCTION}

The COVID-19 pandemic reached subSaharan Africa by the end of February 2020 after it was declared a Public Health Emergency of International Concern by the WHO on 30 January 2020. ${ }^{1}$ With high levels of poverty and generally fragile health systems, sub-Saharan Africa is facing a complex regional COVID-19 epidemic and could also become a difficult-to-control virus reservoir, from where COVID-19 may be reintroduced to other regions that may have achieved control. $^{1-4}$ Economic and cultural conditions may contribute to perpetuating the spread of the virus in these environments. ${ }^{1-4}$ Generalised health system weaknesses and the lack of large-scale COVID-19 testing capacity also prevent the region from assessing the true magnitude of the pandemic at national and supranational levels and from developing a well-targeted strategy and adequate response. $^{35}$

In particular, the lack of a vaccine and effective treatment makes COVID-19 a major global threat. ${ }^{6}$ This has pushed countries around the world to consider the implementation of strict non-pharmaceutical interventions as a priority to fight this pandemic. Such 
interventions include the (mandatory) use of face masks, physical distancing, regular handwashing and the use of hydroalcoholic solution for disinfection. These measures have proven to be effective in controlling epidemics caused by other respiratory viruses such as influenza, SARS and Middle East respiratory syndrome in China, Korea, Taiwan and other countries. ${ }^{7-11}$

\section{Public health context in the Democratic Republic of the Congo} The Democratic Republic of the Congo (DRC) has a recent history of armed civil unrest and is currently confronted with residual armed conflicts in the eastern part of the country. This country is known for its conflicts, ever-present United Nations peacekeeping missions and ongoing or recent outbreaks of vaccine-preventable diseases including measles, polio, cholera and yellow fever. The country is ranked second in Africa in terms of tuberculosis burden, is endemic for malaria and has a $1.2 \%$ HIV prevalence. ${ }^{2}$ Damage to, and depletion of, the DRC's rainforests, exacerbated by war-related displacement of the population to forests, poaching, illegal lumber trade and artisanal mining, continues to precipitate episodic contact of people with animal reservoirs of other viruses including Ebola and Monkeypox.

The eastern part of the DRC has experienced a longrunning Ebola virus epidemic since August 2018. ${ }^{2} 4$ Insecurity made the control of Ebola difficult, and the epidemic was finally halted only in late June 2020. Such a context raises concerns that COVID- 19 would be very complicated to control in the DRC. ${ }^{24}$ The DRC government implemented mandatory use of face mask and physical distancing since 20 April 2020. COVID-19 mass testing is highly recommended by the government, although not sufficiently available. ${ }^{5}$ Other preventive measures that were implemented included closing schools, churches and all country borders; forbidding gatherings of more than 50 people; and limiting the number of passengers in public transportation. COVID-19 testing is only available in six cities, namely, Kinshasa, Matadi, Lubumbashi, Goma, Kolwezi and Mbandaka, with a very low daily testing rate of about 900 tests per day for a population of more than 89 million $^{212}$

Understanding the feasibility of, and adherence to, non-pharmaceutical interventions for COVID-19 is essential for both health system planning and preparedness, and modelling exercises predicting the further evolution of the pandemic at national and local levels. We, therefore, aimed to assess the level of adherence to COVID-19 preventive measures in the DRC and to identify factors associated with non-adherence.

\section{METHODS}

\section{Study setting}

The DRC is the largest country in the Central African region, with an estimated population of 89 million, a total fertility rate of six children born per woman and a life expectancy of 61.6 years. The population of the DRC is relatively young: $62.7 \%$ are between 0 and 24 years, $30.9 \%$ are between 25 and 54 years and $6.3 \%$ are aged $\geq 55$ years. ${ }^{2}$ The country is composed of 26 provinces and shares borders with nine countries. In terms of the operational health system structure, the DRC has 516 health zones. Totally, $46 \%$ of the population live in urban areas, with more than 10 million people living in Kinshasa alone. ${ }^{2}$ Already earlier, on 18 March 2020, when there were only very few COVID-19 cases, the DRC decided to close its borders for incoming travellers and close all crowded events (churches, markets, bars, restaurants and dance clubs) where superspreading events could take place. As of July 2020, the COVID-19 epidemic in the DRC was still mainly concentrated in Kinshasa, especially in La Gombe commune and a few bordering areas. The virus had been spreading wider in the provinces, but there have been only a few confirmed cases outside Kinshasa.

\section{Study design, population and sampling}

An online population-based survey was conducted from 23 April to 8 June 2020 in 22 provinces of the DRC. This study was part of a series of surveys organised by an International Consortium (International Citizen Project COVID-19 (ICPCovid); http://www.icpcovid.com) in low-income countries and low/middle-income countries to monitor the degree to which people aged $\geq 18$ years adhere to COVID-19 preventive measures.

A web-based online questionnaire (see online supplemental material), available at https:/ /www.icpcovid.com/ $\mathrm{fr} /$ country/congo-kinshasa, was used. The questionnaire proposed by the ICPCovid consortium was translated from English to French, adapted and pretested for use in the DRC. ${ }^{13}$ The link was disseminated via social media platforms such as WhatsApp. On clicking on the link, the potential participant was informed about the study objectives, data confidentiality and consent form. Mindful of the low internet penetration and mobile connections in the country (19\% and $40 \%$ of the total population, respectively, as of January $2020^{14}$ ), we anticipated a low number of respondents to the online survey. To increase participation, one to four study assistants were used in each province to assist potential study candidates who had no access to the internet or had difficulties in filling out the form. The study assistants were recruited from among students in medical schools and the Kinshasa School of Public Health, and were trained in data collection procedures and ethics with an emphasis on COVID-19 prevention measures to be respected. Personal protective equipment and mobile internet bundles were provided to the study assistants, who were thereafter deployed to recruit potential participants. Study assistants used WhatsApp to motivate persons in their network to participate in the survey. Moreover, they were asked to interview the first 60 people they met in the street. Study assistants received financial support to cover transportation and mobile internet, but the persons interviewed did not receive any incentive. Participants' responses were either recorded by the study assistants or entered directly by the participants. Where 
needed, the study assistants shared their internet access to enable participants to access the online questionnaire. Both convenience sampling (surveyors themselves contacted potential participants in different districts) and snowball sampling (the participants were requested to share the link of the questionnaire with their contacts) methods were used. The required sample size to detect the anticipated frequency of $18 \%$ of non-adherence as reported by Reuben et $a l^{15}$ with $80 \%$ power and 0.05 significance levels was calculated to be a minimum of 354 participants per province.

The survey tool included questions on demographic characteristics such as age, sex, educational level and occupation. Adherence to preventive measures was assessed using 10 'yes/no' questions based on the WHO and national guidelines on COVID-19 prevention. These included the following: (1) the use of face mask; (2) physical distancing; (3) coughing or sneezing in the crease of the elbow, or covering mouth and nose with a disposable handkerchief; (4) handwashing/disinfecting right after coughing or sneezing; (5) checking body temperature at least twice a week; (6) regular handwashing during the day; (7) using alcohol-based hand sanitiser during the day; (8) avoid touching face (eyes, nose, mouth); (9) disinfecting phone when getting home; and (10) staying at home when having flu-like symptoms.

Each item was scored 1 if the study participant confirmed that he/she adhered to the measure, or 0 otherwise. We computed adherence scores by summing responses to the above-mentioned 10 questions. The score ranged from 0 to 10. The Bloom's cut-off point was used to classify practices into three levels: inadequate $(<6)$, moderate $(6-8)$ and adequate $(>8-10)$. Subsequently, we grouped moderate and adequate practices into one category tagged adherence, whereas inadequate practices were considered as non-adherence to COVID-19 preventive measures. We also asked questions about the presence or absence of flu-like symptoms during the preceding 14 days, the specific symptom(s) they experienced, whether they had been tested for COVID-19 and the test result.

\section{Data management and analyses}

The completed questionnaires were extracted from the secured server of the ICPCovid website and exported to a Microsoft Excel 2016 spreadsheet for cleaning and coding, and subsequently transferred to STATA V.14.1 (Stata, College Station, Texas, USA) for analysis.

During descriptive analysis, categorical variables were summarised using frequencies and proportions. Continuous variables were summarised using mean and $\mathrm{SD}$ if normally distributed, or median and IQR otherwise.

Multivariate analyses were performed to investigate factors associated with adherence to COVID-19 preventive measures. Our dependent variable was binary (adherence vs non-adherence to preventive measures). The association between dependent and independent variables was determined by OR or adjusted OR, with 95\% CI and $p<0.05$ to determine the statistical significance level.
We used logistic regression analysis, with generalised estimating equations, to control for correlations among study participants in the same province. ${ }^{16}$ The cluster effect was controlled for each province. All variables with a likelihood ratio $\mathrm{p}$ value $<0.25$ in bivariate regression were included in the multivariate analysis. We selected the most performant model throughout a backward stepwise approach, based on the smallest Akaike information criterion. A priori, if a strong correlation was noticed between two independent variables, one of the two was eliminated to avoid multicollinearity. We checked multicollinearity among independent variables by estimating the variance inflation factor. All variance inflation factor values were less than 10 , and multicollinearity was negligible.

We also determined the proportion of persons per province who reported a flu-like episode meeting the WHO COVID-19 diagnostic criteria and the criteria of a newly proposed COVID-19 case definition that includes anosmia/ageusia. ${ }^{17}$ We compared these data with the official number of reported confirmed COVID-19 cases in these provinces.

\section{Patient and Public Involvement}

For this study conducted within the ICPCovid consortium, the methodology for data collection and data collection tools were adapted in collaboration with local stakeholders in the DRC. Local study assistants were involved in the recruitment of participants, and the latter were also encouraged to share the survey link with their networks. The results of the study have been shared with the head of the national COVID-19 task force, and a newsletter will be disseminated via social media platforms to update the public.

\section{RESULTS}

\section{Population characteristics}

This study was conducted among 3427 participants in 22 provinces of the DRC. One respondent reported to be 3 years old; we excluded this person from the data set. The number of respondents in 17 provinces was insufficient to meet the required minimum provincial sample size of 354 participants. Therefore, the data from these provinces were excluded from the analyses and only five provinces were included: Haut Katanga, Kasai-Central, Kasai-Oriental, Kinshasa and North Kivu, with a total of 3268 participants.

The average age of the participants was 36 years (SD: 12.5 ), with $34.7 \%$ of participants being over 40 years of age; women represented $66.5 \%$ of participants; and $39 \%$ reported to belong to the Catholic Church community, $33.4 \%$ to the Protestant/Pentecostal Church community and $2.1 \%$ were Muslims (table 1 ).

\section{Adherence to individual containment measures}

Non-adherence to physical distancing was reported by $1364(41.7 \%)$ participants, with highest rates for nonadherence in Haut Katanga $(79.5 \%)$ and Kasai-Oriental 
Table 1 Sociodemographic characteristics of participants in the Democratic Republic of the Congo Provinces,

n (\%)

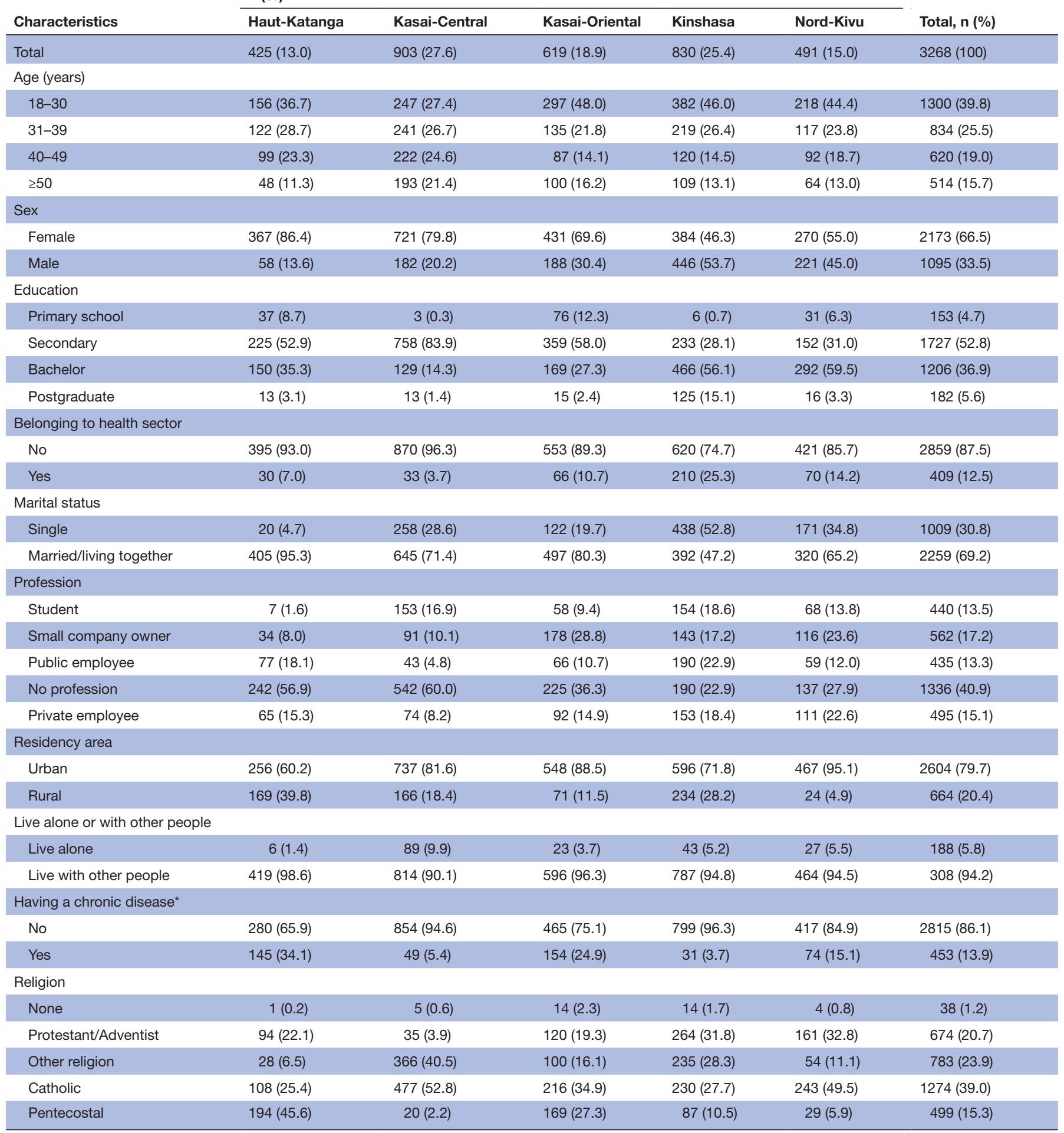

*Hypertension, diabetes, HIV/AIDS and cancer.

$(71.4 \%)$ (table 2). Face masks were not used by 1789 $(54.7 \%)$ participants, with a high percentage of nonusers in Kasaï-Central $(89.3 \%)$, Kasai-Oriental $(83.2 \%)$ and Haut Katanga (81.9\%). In contrast, the percentage of non-users of face masks was low in the city of Kinshasa $(5.2 \%)$ and North Kivu (15.7\%) (table 2).
Regular handwashing was not practised by 501 (15.3\%) participants. The non-adherence to this measure differed between provinces: $57.2 \%$ in Haut Katanga, $21.5 \%$ in Kasai-Oriental, $5.3 \%$ in the city of Kinshasa, $8.6 \%$ in North Kivu and $4.3 \%$ in Kasai-Central (table 2). Not using hand gels was reported by $1573(48.1 \%)$ participants: 
Table 2 Adherence to preventive measures

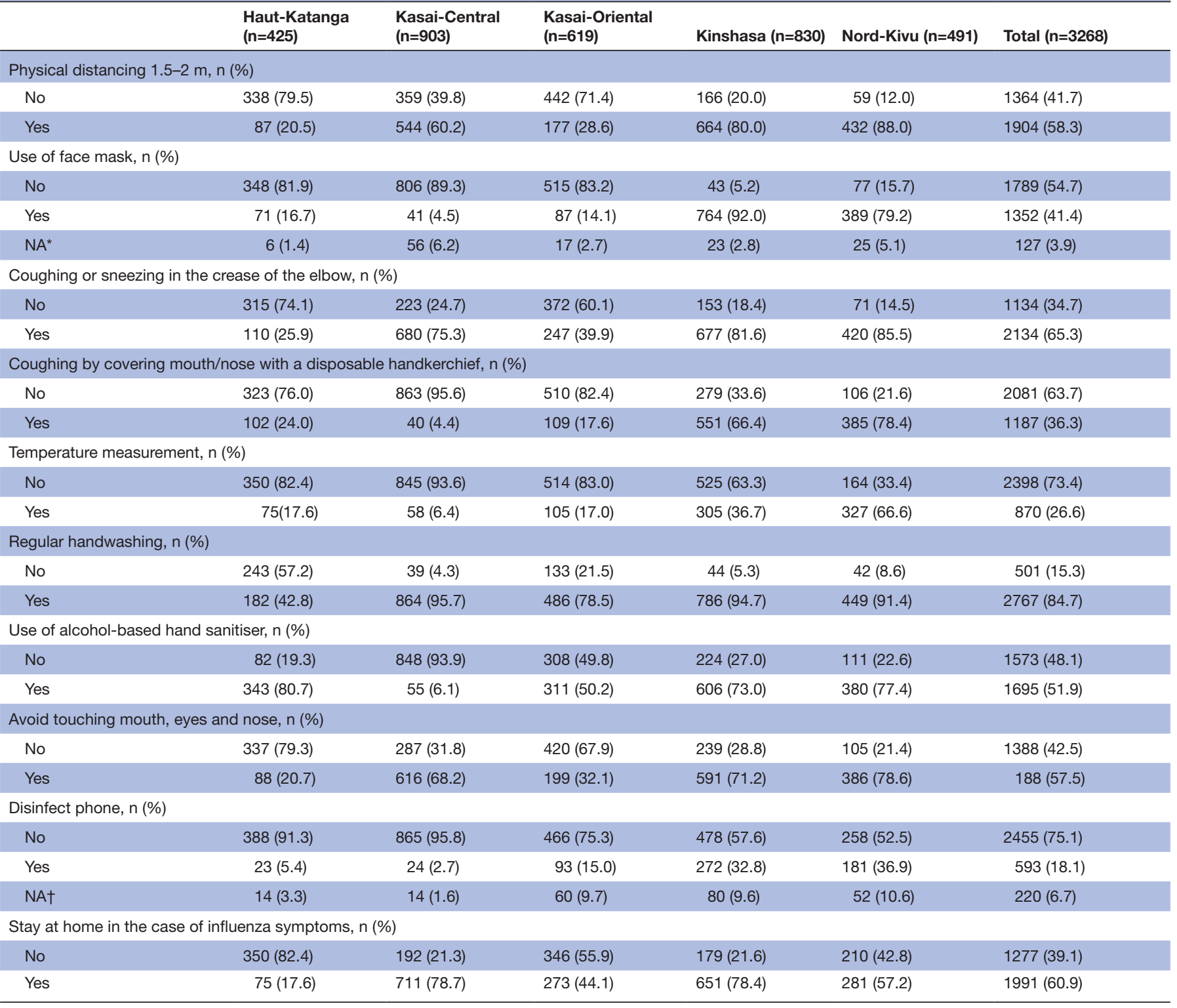

*Do not go out of the house.

†Do not own phones.

93.9\% in Kasai-Central, $49.8 \%$ in Kasaï-Oriental, $19.3 \%$ in Haut Katanga, $27.0 \%$ in Kinshasa and $22.6 \%$ in Nord Kivu (table 2).

Of all the participants, $2455(75.1 \%)$ reported that they did not disinfect their phones when they get back home. The proportions of those who did not disinfect phones in each province were $95.8 \%$ in Kasai-Central, 91.3\% in Haut-Katanga, $75.3 \%$ in Kasai-Oriental, $57.6 \%$ in Kinshasa and $52.5 \%$ in North Kivu (table 2).

Participants' characteristics associated with non-adherence Of the 3268 analysed responses, 1972 (60.3\%) had an adherence score of less than 6 , considered as poor adherence to the COVID-19 preventive measures.

The multivariate analysis revealed that participants without university education had higher odds for non-adherence to the COVID-19 preventive measures $(\mathrm{OR}=2.43,95 \% \mathrm{CI}=2.08$ to 2.84$)$. Similarly, participants who lived with one or more housemates were more likely to adhere poorly to the preventive measures $(\mathrm{OR}=1.13$, $95 \% \mathrm{CI}=1.05$ to 1.83 ) compared with those who were living alone. Being students/jobless and living with sexual partner (either married or cohabiting) were also associated with non-adherence to COVID-19 preventive measures (table 3).

The proportion of suspected and confirmed COVID-19 infected respondents per province

The proportion of suspected and confirmed COVID-19 infected respondents was the highest in Haut-Katanga but very low in Kasai Central and Nord Kivu (table 4). Only $3(3.1 \%)$ out of 93 persons meeting a COVID-19 WHO 
Table 3 Factors associated with poor adherence to COVID-19 preventive measures in the Democratic Republic of the Congo

\begin{tabular}{lll}
\hline Factor & $\begin{array}{l}\text { Crude OR } \\
\text { (95\% Cl) }\end{array}$ & Adjusted OR (95\% Cl) \\
\hline$\geq$ University & 1 & 1 \\
\hline$\leq$ Secondary & $2.99(2.51$ to 3.56$)$ & $2.43(2.08$ to 2.84$)$ \\
\hline Male & 1 & 1 \\
\hline Female & $1.51(1.33$ to 1.71$)$ & $1.14(0.99$ to 1.30$)$ \\
\hline Live alone & 1 & 1 \\
\hline Live with other(s) & $1.67(1.33$ to 2.09$)$ & $1.39(1.06$ to 1.83$)$ \\
\hline Student/jobless & 1 & 1 \\
\hline Private employee & $0.61(0.53$ to 0.71$)$ & $0.76(0.66$ to 0.88$)$ \\
\hline Public employee & $0.44(0.37$ to 0.53$)$ & $0.69(0.57$ to 0.86$)$ \\
\hline Single/separated & 1 & 1 \\
\hline Married/partner & $1.13(1.00$ to 1.28$)$ & $1.20(1.03$ to 1.40$)$ \\
\hline Healthcare worker & 1 & 1 \\
\hline Not healthcare worker & $2.55(2.15$ to 3.01$)$ & $1.85(1.52$ to 2.27$)$ \\
\hline With a chronic disease & 1 & 1 \\
\hline No chronic disease & $0.90(0.76$ to 1.06$)$ & $1.03(0.86$ to 1.23$)$ \\
\hline
\end{tabular}

clinical case definition including anosmia/ageusia were tested positive for SARS-CoV-2.

\section{DISCUSSION}

Our study found an overall non-adherence to preventive measures of $60.3 \%$ among adults in the DRC. COVID-19 preventive behaviour varied between the provinces. Physical distancing, which has demonstrated its efficacy in reducing viral transmission, ${ }^{89}$ was well observed only in Kinshasa, North Kivu and Kasai-Central, with nonadherence rates of $20 \%, 12 \%$ and $40 \%$, respectively. This finding was expected in the city of Kinshasa, which as the capital of the country has the highest number of COVID-19 cases and was allocated more human, logistical and financial resources than other provinces. The low non-adherence to physical distancing in North Kivu may be explained by the experience of the recent Ebola epidemics. $^{2}{ }^{18}$ Kasai-Central also experienced an Ebola epidemic, but it was a very small one.

Respondents from the Ebola-stricken provinces of North Kivu and Kasai-Central also frequently observed hand hygiene. During all Ebola epidemics in the DRC, handwashing was strongly encouraged given that it was the most affordable preventive strategy, even though running water is scarcely available in some areas. ${ }^{18}$ Provinces that had not yet been exposed to Ebola, such as Haut-Katanga and Kasai-Oriental, were often non-adherent to regular handwashing. It is important to ensure that lessons learnt in North-Kivu with Ebola are shared with other provinces to prepare them for the emergence and re-emergence of epidemics that require similar preventive measures. ${ }^{4}{ }^{19}$ The Ebola model should be seen as an important achievement of the DRC and should be used as a tool to enhance disease prevention and control of future epidemics, not only in the DRC but also elsewhere. ${ }^{419}$

Hand sanitiser use was very low in the two provinces of Kasaï. Poverty in these provinces could explain the unavailability of hand sanitisers. Overall, only $18.1 \%$ of the participants reported that they disinfected their phones. This information does not seem to be relayed by communicators who raise awareness to fight COVID-19.

In view of the suboptimal adherence to physical distancing in the majority of our study sites, it is very important to promote universal face masking as a compensatory preventive measure. ${ }^{20}$ Unfortunately, overall non-adherence to mask use was also high in this study (54.7\%). In Kinshasa and North Kivu, there were fewer non-users of face masks, $8 \%$ and $19.8 \%$, respectively. However, we do not know whether those who reported wearing face masks did so consistently. We speculate that the higher use of face mask in Kinshasa is explained by a higher perceived risk of COVID-19 infection, especially in the community of La Gombe than in the other provinces. Moreover, respondents were mainly university graduates, and 89 were medical students, who were probably well informed about the COVID-19 epidemic. Also, economic constraints in buying face masks might be less of a burden for university graduates. Observed face mask use in

\begin{tabular}{|c|c|c|c|c|c|c|}
\hline & $\begin{array}{l}\text { Haut-Katanga } \\
(n=425)\end{array}$ & Kasai-Central $(n=903)$ & $\begin{array}{l}\text { Kasai-Oriental } \\
(n=559)\end{array}$ & Kinshasa $(n=810)$ & $\begin{array}{l}\text { Nord-Kivu } \\
(\mathrm{n}=488)\end{array}$ & Total $(n=3058)$ \\
\hline Meeting WHO case definition, ${ }^{*} n(\%)$ & $116(27)$ & $20(2)$ & $60(10)$ & $12(1)$ & $3(1)$ & $211(6)$ \\
\hline Meeting new case definitiont, $\mathrm{n}(\%)$ & $128(30)$ & $20(2)$ & $69(11)$ & $17(2)$ & $7(1)$ & $241(7)$ \\
\hline Anosmia, n (\%) & $9(2)$ & $1(<1)$ & $2(<1)$ & $9(1)$ & $3(1)$ & $24(1)$ \\
\hline Ageusia, n (\%) & $33(8)$ & $1(<1)$ & $16(3)$ & $14(2)$ & $5(1)$ & $69(2)$ \\
\hline $\begin{array}{l}\text { Tested for COVID-19, } \\
\mathrm{n}(\%)\end{array}$ & $7(2)$ & 0 & $2(<1)$ & $24(3)$ & $2(<1)$ & $35(1)$ \\
\hline Positive & $2(29)$ & 0 & $1(50)$ & 0 & 0 & $3(9)$ \\
\hline Negative & $5(71)$ & 0 & $1(50)$ & 0 & 0 & $32(91)$ \\
\hline
\end{tabular}

*Individuals with fever AND at least one respiratory symptom (dry cough, productive cough, shortness of breath, sore throat, coryza). Contacts/epidemiological links not taken into consideration.

tIndividuals with (fever OR anosmia/ageusia) AND at least one respiratory symptom (dry cough, productive cough, shortness of breath, sore throat, coryza). Contacts/epidemiological links not taken into consideration. 
suburban areas of Kinshasa is reported to be much lower, and there are anecdotal reports that people with a mask are often verbally abused. This may be related to misconceptions fuelled by rumours and fake news. In such areas, many people do not believe COVID-19 is present in the DRC and that it is all a plot 'to get donor money'.

In Kasai-Central, Kasai-Oriental and Haut Katanga, the use of face mask was very low, $10.7 \%, 16.8 \%$ and $18.1 \%$, respectively. An explanation could be that these poor provinces, in contrast with Kinshasa and North Kivu, did not receive a lot of support from international organisations in terms of face mask distribution as well as streamlined training for healthcare workers to improve health promotion. The reasons for the low use of face mask in Haut-Katanga, which is one of the richest provinces in the DRC, warrant further investigation. It may be that the population in this province is not convinced that COVID-19 is a serious health problem. A survey in April 2020 among sellers and customers frequenting the food sections of 10 public markets in three large cities in this province showed that preventive practices were rarely in place. Moreover, $88 \%$ of the persons interviewed had no confidence in the government's ability to manage the pandemic. Only $30 \%$ of participants had correct knowledge of COVID- $19 \%$, and $98 \%$ were concerned about the increase in food insecurity associated with the lockdown measures. $^{21}$

In North Kivu, the reported use of face mask was fairly high $(79.2 \%)$. However, during surveys conducted in May 2020 in Bukavu (South Kivu), practically no mask use was observed despite repeated recommendations from the health authorities and good awareness of the importance of these measures among the local population. ${ }^{22}$

The official reports that showed higher COVID-19related morbidity and mortality in Kinshasa may have motivated the people in Kinshasa to wear face masks. A modelling study suggested that proper use of face mask is able to reduce the risk of COVID-19 transmission by $79 \%{ }^{11}$ Therefore, it is important to identify the reasons for not using face masks and to strengthen the confidence of the population in effective preventive measures through local communication. ${ }^{19}$ We recommend subsidising the local manufacturing of masks to avoid stock shortages. ${ }^{23}$ A public-private partnership initiative could increase the availability of masks, for example, in Haut-Katanga, by involving mining companies. $^{424}$

The postconflict context followed by current political vicissitudes in the DRC makes the situation vulnerable with regard to the spread of COVID-19. For example, by the end of June 2020 and early July 2020, there were political demonstrations in Kinshasa as well as in other cities of the country such as Lubumbashi and Mbuji-Mayi, related to the legislative proposals on the reform of the judicial system in the DRC. These demonstrations took place while the country was still in a state of emergency, and COVID-19 preventive measures were rarely observed by protesters. There is a huge need to strengthen adherence with these protective measures against COVID-19, for fear that the virus becomes difficult to control in the DRC. ${ }^{24}$

A low education level was associated with nonadherence. Several studies have demonstrated the association between low levels of education and the nonadoption of preventive behaviour. ${ }^{25} 26$ Therefore, community sensitisation should target the less educated, address them in their local language and use local role models and teachers.

Students/jobless participants were more likely to be non-adherent. The reasons may be that companies and other public workplaces enforced the implementation of preventive measures by making face masks and physical distancing compulsory as required by the government for fear of sanctions. ${ }^{7-9}$ Participants who were married or living with a partner had higher odds for non-adherence compared with those who were single. The reason for this is unclear.

Only a minority of the participants who reported symptoms suggesting COVID-19 infection were tested. It is recommended to further decentralise COVID-19 testing in the DRC and to prioritise those who are living in households with people over 60 years of age to reduce COVID-19 transmission in those families to prevent COVID-19-related mortality. ${ }^{27} 28$

Respondents who were healthcare workers reported good preventive behaviour, most likely because they were already well aware and trained to observe preventive measures for COVID-19 and other diseases. In addition, healthcare personnel are responsible for training and raising awareness among the patients/communities and are expected to show a good example to the patients. ${ }^{29} 30$

Our study has several limitations. First, our study respondents cannot be considered to be representative of the general population living in the provinces where the survey was done. Indeed, respondents were mainly recruited from among more educated individuals who often had more access to the internet and smartphones. Moreover, self-reports may be influenced by recall bias and social desirability. Also, the fact the questionnaire was completed over a 6-week period in a context of a rapidly changing COVID-19 landscape may render the interpretation of our findings and comparisons across provinces difficult. However, more than $80 \%$ of the recruitment occurred during the last 3 weeks of the data collection after the research assistants were included in the process. During these last 3 weeks, data collection took place simultaneously in all the provinces. Another limitation is that we did not ask why certain people did not adhere to the preventive measures. We also did not investigate the role of psychological variables that may affect adherence with preventive measures, such as the perceived difficulty of doing so, boredom and self-control. ${ }^{31}$ The fact that relatively few persons in Kinshasa reported flu-like symptoms is in contrast with the high number of COVID-19 cases officially reported in the capital. The reason for this could be that most respondents were living outside the most affected area of Kinshasa (La Gombe) and because 
persons living in Kinshasa were the first to complete the questionnaire at an early phase of the epidemic.

Despite the fact that preventive measures in the DRC are not followed by large parts of the population, the pandemic seems not to be progressing. As of 23 October, the cumulative number of COVID-19 cases was 11 096, with 19 new cases identified in 24 hours and only 304 cumulative deaths. ${ }^{32}$ These low numbers cannot be explained by the still limited COVID-19 testing capacity in the DRC. Indeed, hospitals in the DRC have not reported huge numbers of hospitalised patients with COVID-19 symptoms. With the exception of South Africa, in many sub-Saharan African countries, an epidemic peak of COVID-19 infections comparable as in Europe, USA or South America was never observed, and currently a decrease in the number of new infections is being observed. By October, Africa, which makes up 17\% of the global population, had recorded just 3.5\% of COVID-19 deaths. ${ }^{33}$ Many hypotheses have been proposed to explain this low COVID-19-related morbidity and mortality in subSaharan Africa, such as under-reporting of cases, early effective strict lockdown measures, the young age of the population, previous exposure to other coronaviruses, a strong immune system because of frequent exposure to pathogens, and climatological and genetic factors; however, a clear explanation is still lacking. ${ }^{34}$

\section{CONCLUSION}

The level of adherence to preventive measures against COVID-19 among respondents in this survey was suboptimal, despite the compulsory guidelines instituted by the DRC government. Regional disparities in the implementation of these measures are remarkable. There is an urgent need to further explore the reasons for these disparities to implement an effective response and reinforce COVID-19 prevention. To this end, community engagement and involvement should be strongly encouraged as the key to success. We recommend implementing public-private partnerships, peer support approaches and positive deviance to reverse the current trends of nonadherence. Moreover, future research should investigate why the frequent non-adherence to preventive measures in the DRC, as reported in this study, has not resulted in a relatively higher COVID-19 disease burden and mortality like in Europe and the Americas.

\footnotetext{
Author affiliations

${ }^{1}$ Ecole de Santé Publique, Universite de Kinshasa Faculte de Medecine, Kinshasa, Democratic Republic of the Congo

${ }^{2}$ Pôle d'Épidémiologie et Biostatistique, Université catholique de Louvain (UCLouvain), Institut de Recherche Expérimentale et Clinique (IREC), Brussels, Belgium

${ }^{3}$ Department of Tropical Medicine, Universite de Kinshasa Faculte de Medecine, Kinshasa, Democratic Republic of the Congo

${ }^{4}$ Global Health Institute, University of Antwerp, Antwerp, Belgium

${ }^{5}$ Public Health, Institute of Tropical Medicine, Antwerp, Belgium

${ }^{6}$ Direction of the institute, Institut National de Recherche Biomédicale, Kinshasa, Democratic Republic of the Congo
}

Acknowledgements We thank all the participants of this study.

Contributors JDD, HMM, JNSF and RC worked and contributed substantially to the study conception and design. DN and CL contributed significantly to data collection. JDD, DN, DN and RVB conducted data analysis and interpretations. JDD and RC developed the draft manuscript. RC supervised the manuscript development. RC, HMM, JNSF, DN, CL, RVB, AT, WVD and JJM contributed significantly to the manuscript conception and review. All co-authors provided approval of the submitted version and agreed to be accountable for all aspects of the manuscript.

Funding This research was supported by the European Research Council (ERC 671055) and VLIRUOS (Global Minds programme).

Competing interests None declared.

Patient consent for publication Not required.

Ethics approval The approval was obtained from the DRC National Ethical Committee prior to any implementation of the research (CNES N ${ }^{\circ} 175 / \mathrm{CNES} / \mathrm{BN} /$ $\mathrm{PMMF} / 2020)$. To ensure confidentiality, data were collected online anonymously and were only available to study investigators using passwords. The study investigators are certified on ethical training as well as good clinical practices, and they are bound by professional secrecy with regard to all the information collected during this study. All participants provided an e-consent before submitting their responses.

Provenance and peer review Not commissioned; externally peer reviewed.

Data availability statement Data are available upon reasonable request. Data are available on the International Consortium (International Citizen Project COVID-19 (ICPcovid): http://www.icpcovid.com) website and could be used by other investigators on request. Deidentified participant data are available. My ORCID identifier is 0000-0002-3022-4879 and my email is: jditekemenaotmail.fr.

Supplemental material This content has been supplied by the author(s). It has not been vetted by BMJ Publishing Group Limited (BMJ) and may not have been peer-reviewed. Any opinions or recommendations discussed are solely those of the author(s) and are not endorsed by BMJ. BMJ disclaims all liability and responsibility arising from any reliance placed on the content. Where the content includes any translated material, BMJ does not warrant the accuracy and reliability of the translations (including but not limited to local regulations, clinical guidelines, terminology, drug names and drug dosages), and is not responsible for any error and/or omissions arising from translation and adaptation or otherwise.

Open access This is an open access article distributed in accordance with the Creative Commons Attribution Non Commercial (CC BY-NC 4.0) license, which permits others to distribute, remix, adapt, build upon this work non-commercially, and license their derivative works on different terms, provided the original work is properly cited, appropriate credit is given, any changes made indicated, and the use is non-commercial. See: http://creativecommons.org/licenses/by-nc/4.0/.

\section{ORCID iDs}

John Dinanga Ditekemena http://orcid.org/0000-0002-3022-4879

Joseph Nelson Fodjo Siewe http://orcid.org/0000-0003-3544-1239

\section{REFERENCES}

1 World Health Organization. Statement on the second meeting of the International health regulations (2005) emergency Committee regarding the outbreak of novel coronavirus (2019-nCoV), 2020. Available: https://www.who.int/news-room/detail/30-01-2020statement-on-the-second-meeting-of-the-international-healthregulations-(2005)-emergency-committee-regarding-the-outbreak-ofnovel-coronavirus-(2019-ncov) [Accessed 24 Jul 2020].

2 Ditekemena J, Doumbia S, Ebrahim SH. COVID-19's final frontier: The central Africa region. Travel Med Infect Dis 2020;37:101694.

3 Elhadi M, Msherghi A, Alkeelani M, et al. Concerns for low-resource countries, with under-prepared intensive care units, facing the COVID-19 pandemic. Infect Dis Health 2020;25:227-32.

4 Ditekemena J. COVID-19 amidst Ebola's retreat. Science 2020;368:445.

5 Kobia F, Gitaka J. COVID-19: Are Africa's diagnostic challenges blunting response effectiveness? AAS open research 2020:3 http:// europepmc.org/abstract/MED/32399515;

6 Tobaiqy M, Qashqary M, Al-Dahery S, et al. Therapeutic management of patients with COVID-19: a systematic review. Infect Prevent Pract 2020;2:100061.

7 Wang Q, Yu C. The role of masks and respirator protection against SARS-CoV-2. Infect Control Hosp Epidemiol 2020;41:746-7. 
8 Noh JY, Seong H, Yoon JG, et al. Social distancing against COVID-19: implication for the control of influenza. J Korean Med Sci 2020;35:e182.

9 Jang WM, Jang DH, Lee JY. Social distancing and Transmissionreducing practices during the 2019 coronavirus disease and 2015 middle East respiratory syndrome coronavirus outbreaks in Korea. $J$ Korean Med Sci 2020;35:e220.

10 World Health Organization. Advice on the use of masks in the context of COVID-19, interim guidance, 2020. Available: https://apps.who.int/ iris/handle/10665/332293 [Accessed 24 Jul 2020].

11 Wang $\mathrm{Y}$, Tian $\mathrm{H}$, Zhang $\mathrm{L}$, et al. Reduction of secondary transmission of SARS-CoV-2 in households by face mask use, disinfection and social distancing: a cohort study in Beijing, China. BMJ Glob Health 2020;5:e002794.

12 Juma CA, Mushabaa NK, Abdu Salam F, et al. COVID-19: the current situation in the Democratic Republic of Congo. Am J Trop Med Hyg 2020;103:2168-70.

13 Ahmed MAM, Siewe Fodjo JN, Gele AA, et al. COVID-19 in Somalia: adherence to preventive measures and evolution of the disease burden. Pathogens 2020;9:735.

14 Kemp S. Digital 2020: the Democratic Republic of Congo. Kinshasa, 2020. Available: https://datareportal.com/reports/digital-2020democratic-republic-of-the-congo

15 Reuben RC, Danladi MMA, Saleh DA, et al. Knowledge, attitudes and practices towards COVID-19: an epidemiological survey in northcentral Nigeria. J Community Health 2020. doi:10.1007/s10900-02000881-1. [Epub ahead of print: 07 Jul 2020].

16 Hendricks SA, Wassell JT, Collins JW, et al. Power determination for geographically clustered data using generalized estimating equations. Stat Med 1996;15:1951-60.

17 World Health Organization. Who COVID-19: case definitions case definitions. updated in public health surveillance for COVID-19. Geneva: WHO, 2020. https://www.who.int/publications-detailredirect/who-2019-nCoV-surveillanceguidance-2020.7

18 Schwartz DA. Being pregnant during the Kivu Ebola virus outbreak in DR Congo: the rVSV-ZEBOV vaccine and its accessibility by mothers and infants during humanitarian crises and in conflict areas. Vaccines 2020;8:38.

19 West R, Michie S, Rubin GJ, et al. Applying principles of behaviour change to reduce SARS-CoV-2 transmission. Nat Hum Behav 2020;4:451-9.

20 Siewe Fodjo JN, Pengpid S, Villela EFdeM, et al. Mass masking as a way to contain COVID-19 and exit lockdown in low- and middleincome countries. J Infect 2020;81:e1-5.

21 Carsi Kuhangana T, Kamanda Mbayo C, Pyana Kitenge J, et al. COVID-19 pandemic: knowledge and attitudes in public markets in the former Katanga Province of the Democratic Republic of Congo. Int J Environ Res Public Health 2020;17:E7441.

22 Wimba PM, Bazeboso J-A, Katchunga PB, et al. A dashboard for monitoring preventive measures in response to COVID-19 outbreak in the Democratic Republic of Congo. Trop Med Health 2020;48:74.

23 Wang J, Pan L, Tang S, et al. Mask use during COVID-19: a risk adjusted strategy. Environ Pollut 2020;266:115099.

24 Nishtar S. Public - private 'partnerships' in health - a global call to action. Health Res Policy Syst 2004;2:5.

25 Miller LC, Joshi N, Lohani M, et al. Women's education level amplifies the effects of a livelihoods-based intervention on household wealth, child diet, and child growth in rural Nepal. Int J Equity Health 2017;16:183-83.

26 Acharya P, Khanal V. The effect of mother's educational status on early initiation of breastfeeding: further analysis of three consecutive Nepal demographic and health surveys. BMC Public Health 2015;15:1069-69.

27 Esbin MN, Whitney ON, Chong S, et al. Overcoming the bottleneck to widespread testing: a rapid review of nucleic acid testing approaches for COVID-19 detection. RNA 2020;26:771-83.

28 Gargaglioni LH, Marques DA. Let's talk about sex in the context of COVID-19. J Appl Physiol 2020;128:1533-8.

29 Rowe AK, Rowe SY, Peters DH, et al. Effectiveness of strategies to improve health-care provider practices in low-income and middle-income countries: a systematic review. Lancet Glob Health 2018;6:e1163-75.

30 Chu DK, Akl EA, Duda S, et al. Physical distancing, face masks, and eye protection to prevent person-to-person transmission of SARS-CoV-2 and COVID-19: a systematic review and meta-analysis. Lancet 2020;395:1973-87.

31 Wolff W, Martarelli CS, Schüler J, et al. High Boredom proneness and low trait self-control impair adherence to social distancing guidelines during the COVID-19 pandemic. Int J Environ Res Public Health 2020;17:5420.

32 World Health Organization. Weekly epidemiological update 20 October 2020. Geneva: WHO, 2020. https://www.who.int/ publications/m/item/weekly-epidemiological-update20-october2020

33 Pilling D. How Africa fought the pandemic -and what coronavirus has taught the world. financial times, 2020. Available: https://www.ft. com/content/c0badd91-a395-4644-a734-316e71d60bf7

34 Van Damme W, Dahake R, Delamou A, et al. The COVID-19 pandemic: diverse contexts; different epidemics-how and why? BMJ Glob Health 2020;5:e003098. 